\title{
An Empirical Study on Primary Teachers' Information Technology Learning Difficulties Structure
}

\author{
Huang Ming-Zong \\ Department of Industrial Technology Education, National Kaohsiung Normal University \\ Kaohsiung 82444, Taiwan \\ Tel: 886-9-6324-1003Ｅ-mail: warrickhuang@gmail.com
}

\begin{abstract}
The purpose of this study is to establish a scale with reliability and validity about information technology learning difficulties through a series of precise analytical procedures. Taking primary teachers as the subject of research and adopting the method of stratification sampling, the author made two questionnaire surveys. First of all, in the pre-examination questionnaire, he altogether sent out 205 questionnaires, and took back 164 effective questionnaires. Through project analysis, reliability test and exploratory factor analysis, the formal questionnaire was formed. Then, he again released 682 questionnaires and took back 473 effective questionnaires, with an effective recovery rate of $69.4 \%$. After confirmatory factor analysis, such three factors as self-competence difficulty, family difficulty and information support difficulty were extracted, and eleven measurement terms were reserved. However, the coefficient $\alpha$ was all above .8 at all levels of the scale and the coefficient $\alpha$ was also above .9 in the whole scale, which indicated perfect internal consistency. As for the verification mode, after correction, its adaptive degree was proved to be benign be means of confirmatory factor analysis. Since the scale in this study was with benign reliability and validity, subsequent researchers may conduct relevant studies based on the scale established in this study.
\end{abstract}

Keywords: Difficulties, Information technology learning, Exploratory factor, Confirmatory factor

\section{Introduction}

\subsection{Research motive}

If matched up with planning of instructional design, application of information technology would work as planned, whereas if design of instruction could refer to development of information technology, reveal its innovation and break through its established nest limitation, the two could more supplement each other, function as they should, integrate information technology into teaching and improve learning efficiency of school children (Wang, Xiaoxuan, 2004). However, the biggest difference between integration of information technology into teaching and application of traditional education technology into teaching lies in the fact that, traditional technology focuses on change of the results, and intends to improve quality or effect of educational outcome through application of technology. What's more, modern education technology concentrates on the process of teaching and learning (Chen, Weihong \& Gao, Xunfang, 2004). Innovation of human beings is unlimited, science and technology evolves at a tremendous pace, and our surrounding life is embraced with products of information technology, so in the high-tech development society, improvement of information technology accomplishment and scientific knowledge is absolutely necessary. Furthermore, learning of primary teachers' information technology will be the important aspect for excellent scientific human resources to excel. However, the greatest incentive of learning is to stimulate the learning motive of learners, so as to achieve the effect of learning, diminish unnecessary learning difficulties and realize effective learning.

There are three sorts of barriers among adult learners, respectively situational barrier, institutional barrier and psychological or dispositional barrier. Situational barrier refers to barrier of an object or the environment in a certain period, including lack of time, inconvenient traffic and factors of children, etc. Institutional barrier refers to factors that may impede participation of learners in an institution, including time sequential routine, and the fact whether one is interested in the region, traffic and curriculum, etc. Individual psychological or dispositional barrier refers to psychological barrier, including personal attitude, concept and values, barrier on participation activities, such as no confidence in learning, etc. (Cross, 1981). In the information society, production of information is fast and explosion of knowledge is resulted, which, in turn, expands the field of learning, and poses great challenges to individuals. Thus, if one does not pursue further learning or knowledge, he may soon be utterly ignorant of certain things, and if he does not learning frequently, there may be no means for him to 
keep up with pace of the times and development of the society (Ministry of Education, 1998). What primary teachers have to teach is a group of small children with curiosity and great thirst for knowledge, so innovative learning is an unchangeable principle for their teaching. However, for compliance with the rapid transition of the era, in addition to enrichment of professional knowledge, if primary teachers exclude information technology learning difficulties and grasp convenience and advantages of information technology, they will be equipped with excellent competitive power than others.

\subsection{Research objective}

The research objective is to increase relative knowledge of self information technology and to use more frequently computers or go Internet to deal with relative design for instructional activities, which is believed to improve innovative competence of teaching. Therefore, it is a topic that deserves to be discussed to come to understand information technology learning difficulties among primary teachers. And the objective of research is to establish and verify the scale of information technology learning difficulties among primary teachers, that is, to measure degree and situation of information technology learning difficulties among primary teachers.

\subsection{Explanation of terms}

1) Information technology: information technology belongs to part of science and technology, which lays emphasis on application of such electronic technology as computer, Internet and communications (including telecommunications and transmission) to data processing, reception, storage and transmission technology.

2) Information technology learning difficulties: the situation in which the process of knowledge acquisition or behavioral change is incomplete, internal frustration or failure feeling is caused and thus one has the state of mind to exclude, give up or reject learning of information technology in the process of self learning in a surrounding embraced with information technology.

3) Confirmatory factor analysis: aimed to explain relevant or co-variation relationship between observed variables, and lay particular stress on examining relationship between assumed observed variables and assumed potential variables.

\section{Research methodology}

\subsection{Compilation of the scale}

There are altogether 15 items in the compiled scale of information technology learning difficulties among primary teachers. After literature review, the first draft of the pre-examined scale was reviewed by scholars and experts in its content validity and adequacy, and then was divided into the three perspectives of self-competence difficulty, family difficulty and information support difficulty after being corrected according to opinions of these experts. As for code numbers of items in the scale and their content, please see Table 1. This scale adopts the scoring method of 5-point Likert scale, and is separated into five options, respectively, quite congruent, congruent, partly congruent, incongruent and quite incongruent, with the scores of successively 5, 4, 3, 2 and 1 . The higher the score is, the higher the degree of congruency of the item.

\section{Insert Table 1 Here}

\subsection{Research sample}

The research sample was Kaohsiung municipal primary teachers, including subject teachers, form teachers, those who are both teacher and group leader, and those who are both teacher and director, etc. According to the statistical information of the status quo of education released on the website of Kaohsiung Board of Education (2009) and the latest data of the school year of 2008 by the Board of Education on March 15, 2009, there were altogether 89 Kaohsiung municipal primary schools, and approximately 5688 primary teachers, which is the population in this research.

The number of people in the pre-examined sample should be equal to three to five times of that in the sub-scale with the most items in the questionnaire (Wu, Minglong \& Tu, Jintang, 2005). In order to avoid non-uniform source of pre-examined data, in this study, the author divided Kaohsiung municipal primary schools into small-size schools, small and medium-size schools, medium and large-scale schools and large-scale schools based on the scale of the schools. Then, the author made a stratified sampling according to scale of the schools and proportion of the teachers. Altogether, he sent out 205 pre-examined questionnaires and took back 169 questionnaires. After check of these questionnaires, he got rid five questionnaires with incomplete answers and unchangeable responses, so he altogether had 164 effective questionnaires, with an availability rate of $80 \%$. After that, he input data of pre-examined questionnaires into the computer, and made a statistical analysis in the reliability and validity with SPSS 16.0 for Windows in its Chinese version. After finishing analysis of 
pre-examined data and correcting the scale, the author made sampling with the same method when he made the confirmatory factor analysis. In questionnaire survey of developing the scale, Nunnally \& Bernstein (1994) believed that the number of 300 samples was appropriate. Thus, in this study, the author sent out 682 questionnaires, and took back 473 effective questionnaires, with an effective recovery rate of $69.4 \%$.

\subsection{Analysis of pre-examined data}

After taking back pre-examined questionnaires, the author firstly made a project analysis in items of the questionnaires to examine their adequacy, which was to calculate the critical ratio (abbreviated as CR value) of each item. In analysis of this research, first of all, the author calculated the total score of each item and ranked all subjects based on their total scores in the pre-examined scale. Then, the author selected $27 \%$ of those with the highest total scores to form a group of high score and $27 \%$ of those with the lowest total scores to form a group of low score. He calculated the average score of each item of all subjects in the two groups and conducted a test for significance of difference. Factor analysis is necessary in order to test the construct validity of the scale, and the so-called construct validity refers to the degree that attitude scale can measure the concept or feature of the theory. The purpose of factor analysis is to find out the potential structure of the scale, reduce the number of items and make these items one group of variables with a small number but related closely (Wu Minglong, 2003).

In this study, the author made a comparison between Kaiser-Meyer-Olkin measure of sampling adequacy test (KMO) and Bartlett sphericity test to determine degree of correlation between items. According to Kaiser (1974), it is acceptable if $\mathrm{KMO}>.70$, and the case when $\mathrm{KMO}>.90$ is optimal. And if Bartlett sphericity test also attains the significance level, then it is proved that the degree of correlation between items is enough for factor analysis. To extract factors with relatively high eigenvalue by means of principal component analysis. The higher the eigenvalue is, the more possible it is for these factors to explain all variance. Kaiser (1974) suggested reserving factors with eigenvalue higher than 1. Besides, Devellis (1991) also recommended applying the Varimax to work out the coefficient of correlation between items and factors, namely, factor loadings, and selecting coefficient with absolute value higher than .50. Finally, the author calculated the Cronbach $\alpha$ value of the whole scale, and the value of $\alpha$ should be higher than 70 to display good internal consistency of the scale.

\subsection{Analysis of formal questionnaire data}

After re-compilation, the second questionnaire survey was conducted on the scale, in which data acquired was employed to make a confirmatory factor analysis with the purpose of verifying the construct validity of the formal scale by means of Linear Structural Relations (LISREL). This study made an evaluation from the three aspects of preliminary fit criteria, overall model fit and fit of internal structure of the model, which is comprehensively stated as follows (Bagozzi \& Yi,1988; Hair, Anderson, Tatham, \& Black, 1998; Bentler,1990; Hong, Thong, Wong, \& Tam,2002; Bentler,1990; Wu, Minglong, 2007):

\subsubsection{Preliminary fit criteria of the model}

1). There should not be any negative error variation. 2). Error variation ought to be above the significance level. 3). Relevant absolute value of parameters can not be too close to 1. 4). Factor loadings can not be too low (lower than .5) or too higher (higher than .95). 5). There should not be any too high standard error of the parameter estimated

If a model runs counter to the above several criteria, it is proved that there may have some problems in definition of this model, so it needs to be re-defined. If estimated results of the model correspond with these criteria, then this model can be further checked for its overall model fit and fit of internal structure of the model.

\subsubsection{Overall model fit (External quality of the model)}

Previously, there have been many a research reports that took as the criterion whether the value of $\chi^{2}$ was significant in evaluation of the overall model fit. However, the value of $\chi^{2}$ may fluctuate with the number of people in the sample. Once the number of people in the sample is too large, almost all models may be rejected. Therefore, in addition to application of $\chi^{2}$, statists have proposed a series of indicators to evaluate the model fit. Table 2 contains some indices frequently used in previous literature to evaluate overall model fit and number range of these indices and desired value.

\section{Insert Table 2 Here}

2.4.3 Fit of internal structure of the model (Internal quality of the model)

Fit of internal structure of model can be said to be the internal quality of a model, with the following frequently used criteria: 
1). Whether constituent reliability of potential variables is above .6. 2). All parameters estimated are above the significance level. 3). The absolute value of standardized residuals ought to be lower than 2.58 .

\section{Research results and discussion}

The objective of this study is to establish and verify the scale of information technology learning difficulties among Kaohsiung municipal primary teachers, and altogether two questionnaire surveys were made. Project analysis and tentative factor analysis were made on data of the first questionnaire survey and confirmatory factor analysis was made on data of the second questionnaire survey, with the following results:

\subsection{Analysis of data in the first questionnaire survey (pre-examination)}

Time limit for response to the questionnaire was from September 7, 2009 to September 25, 2009. The tester altogether sent out 205 questionnaires, and took back 169 questionnaires. After getting rid of questionnaires with incomplete answers, he altogether took back 164 effective questionnaires, with an effective recovery rate of $80 \%$.

\subsubsection{Project analysis}

The author selected the independent sample $t$ to examine whether the scores of the group of high score and the group of low score had attained significant variation. Finally, he found that the critical ratio of all the 15 subjects was between 6.253 and 12.617, which reached the significance level $(\mathrm{p}<0.05)$ and indicated that all these subjects attained the degree for differentiation, as is shown in Table 3.

\section{Insert Table 3 Here}

\subsubsection{Tentative factor analysis}

In order to confirm the potential perspective of the scale, the author made tentative factor analysis after project analysis. First of all, he tested degree of correlation between items and the statistical value of KMO was .884, which was proved to be benign for factor analysis. The eigenvalue of the three factors was respectively 3.648 , 3.509 and 3.222, all above 1. The three factors accounted for an accumulative percent of $69.190 \%$ of the total variation. Through examination of all factors and questions, in the subject $\mathrm{x} 6$ in which there had great difference between the theme and factors, its meaning had differed because of transferring to other factors. And the subject $\mathrm{x} 4$ stretched across two factors. Thus, these two subjects were deleted and a second factor analysis was made.

According to results of the second factor analysis, the statistical value of KMO was .862 , the eigenvalue of all factors was respectively $3.437,2.965$ and 2.718 , and the three factors accounted for an accumulative percentage of $70.156 \%$ of the total variation. Through examination of all factors and questions, naming of the factors corresponded with original construct validity. There were altogether 13 subjects in the scale, and the Cronbach $\alpha$ value of all sub-scales was respectively $.853, .832$ and .879 , whereas the Cronbach $\alpha$ value of the whole scale was .907 , which indicated high internal consistency of the whole scale and all sub-scales, and optimal reliability. As for relevant factor structure and reliability analysis, please refer to Table 4 .

\section{Insert Table 4 Here}

\subsubsection{Perspective implication of the formal scale}

After project analysis and tentative factor analysis, all previous pre-examined items of the scale were reserved to form a formal scale. Definition of all perspectives of the formal scale is as follows: 1). Self-competence difficulty: lack of self-consciousness, interest, competence and information technology quality in participation of information technology learning activities and learning difficulties caused by internal anxiety, tension and scared feelings. 2). Family difficulty: learning difficulties caused by family financial burden, education expenditure of children, family atmosphere, too much expect of the family, too many domestic chores and too narrow and noisy family living space, etc. 3). Information support difficulty: learning difficulties caused by inadequate information technology learning environment (such as wireless network and action learning, etc.), few information technology learning opportunities (such as project work, occupational training institutions and courses, etc.) and low quality of information technology learning peers or lack of objects of enquiry, etc.

\subsection{Analysis of data of the second questionnaire survey}

Time limit for response to the formal questionnaire was from October 18, 2009 to November 15, 2009. The tester altogether sent out 682 questionnaires, and took back 473 questionnaires, with an effective sampling recovery rate of $69.4 \%$. This study firstly made a confirmatory factor analysis in the Linear Structural Relations (LISREL), and if the model fit was not ideal, then this model would be corrected according to the results. After the corrected 
model was put forward, the second confirmatory factor analysis was made to examine the fit of the corrected model.

\subsubsection{The first confirmatory factor analysis}

First of all, in terms of preliminary fit criteria of the model, its variable error was tested, and error variables of all items were all positive, between .22 to .55 , all above the significance level of $p<.001$. Relevant absolute value of parameters estimated was not close to 1 . Factor loadings of variables were from .59 to .86 , all between .50 and .95 , and the biggest standard error estimated of parameters was .096. In terms of overall model fit, the value of $\chi^{2}$ was 535.698, $\chi^{2}$ df 8.64, GFI .842, AGFI .768, RMR .059, SRMR .0716, RMSEA .127, CFI .849, PGFI .574, NFI .834, IFI .850, and NNFI was .810.

Finally, in terms of internal structure fit of model, constituent reliability of potential variables was between .7637 and .8657, all above .6. All parameters estimated attained the significance level, and the absolute value of standardized residuals was all below 2.58 .

In conclusion, fit of the Linear Structural Relations (LISREL) was not quite ideal, and was open for improvement. As mentioned above, correction of Linear Structural Relations (LISREL) can refer to result of confirmatory factor analysis and modification of the indicator recommended. After modification of the indicator by referring to suggestions of measured error of observed variables, the modified indicator of this study is marked as the double-headed arrow in Figure 1. After the assumed model was corrected as above, the second confirmatory factor analysis was made.

\subsubsection{The second confirmatory factor analysis}

It was indicated that error variables of all items were all positive, between .25 to .59 , all above the significance level of $\mathrm{p}<.001$ and relevant absolute value of parameters estimated was not close to 1. Factor loadings of observed variables were all within the standard value of .57 to .88 , and the biggest standard error estimated of parameters was .125 . Hence, preliminary model fit of the corrected model was good.

In terms of overall model fit, the value of $\chi^{2}$ was 113.607, $\chi^{2} / \mathrm{df} 3.070$, GFI .957, AGFI .924, RMR .037, SRMR .0434, RMSEA .066, CFI 968, PGFI .537, NFI .954, IFI .969, and NNFI was .953. Thus, overall model fit of the corrected model was good.

In terms of internal structure fit of model, it was indicated that constituent reliability of potential variables of the corrected model was between .6562 and .8535 , all above .6. All parameters estimated attained the significance level, and the absolute value of standardized residuals was all below 2.58 (See Table 5). Then it can be seen that internal structure fit of the corrected model was good. For the formal scale after correction, please see Table 6.

\section{Insert Table 5 Here}

\section{Insert Figure 1 Here}

\section{Insert Table 6 Here}

\section{Conclusion and recommendation}

\subsection{Conclusion}

This study made an empirical examination on tentative and confirmatory aspects of the scale and checked its fit in the hope of providing government agencies and non-government institutions of all levels in the future with reference for planned activities of information technology learning education.

Altogether, this study made two questionnaire surveys. Project analysis and tentative analysis was made on data of the first questionnaire survey and confirmatory factor analysis was made on data of the second questionnaire survey. It was indicated in the results that, the scale of information technology learning difficulties among primary teachers included self-competence difficulty, family difficulty and information support difficulty. After extraction of items measured, altogether 11 items were reserved, respectively four items belonging to self-competence difficulty, three items belonging to family difficulty and four items belonging to information support difficulty.

As for reliability of the formal scale, self-competence difficulty was .853 , family difficulty was .832 and information support difficulty was .879. The coefficient $\alpha$ of the whole scale was .907 , all above .70, which proved reliability of the scale was good.

In addition, according to the confirmatory factor analysis, after the confirmatory factor analysis model was corrected, its preliminary fit, internal structure fit of model and the overall model fit all approximately 
corresponded with the standard value of evaluation indices, so fit of the corrected model was good. Thus, it can be seen from the analysis results that the formal scale had good construct validity after correction.

\subsection{Recommendation}

1). Information technology learning difficulties and improvement of information technology competence are closely interrelated. The school authorities are recommended to employ this scale and take primary teachers as the subject of test to really realize degree and situation of information technology learning difficulties among primary teachers.

2). Removal of information technology learning difficulties is helpful for improvement of personal information technology learning intention. And it is suggested that subsequent researchers conduct a study on information technology learning difficulties and intention factors so as to understand relationship underlying.

3). In this study, Kaohsiung primary teachers were the major subjects, and forthcoming research may take primary teachers or middle school teachers as the subject to further verify reliability and validity of the scale.

4). Subsequent research may adopt the method of multi-group analysis and verify information technology learning difficulties of different genders so as to further understand differences of different genders.

\section{References}

Bagozzi, R. P., \& Yi, Y. (1988). On the evaluation of structural equation models. Journal of the Academy of Marketing Science, 16:74-94.

Bentler, P. M. (1990). Comparative fit indices in structural models. Psychological Bulletin, 107:238-246.

Board of Education of Kaohsiung. Statistical Information of Educational Status Quo. [Online] Available: http://163.32.250.1:8000/Members/grp07/new_page_3.htm (September 5, 2009).

Chen, Weihong \& Gao, Xunfang. (2004). Primary Investigation into Standards of Evaluation on Implementation Effect of Information Education. Education Research Monthly, 122:133-147.

Cross, K. P.. (1981). Adults as Learners. San Francisco: Jossey-Bass.

Devellis, R. F. (1991). Scale development: Theory and Applications. Thousand Oaks, CA: Sage.

Everitt, B. \& Dunn, G. (2001). Applied multivariate data analysis. New York: Oxford.

Hair, J. F., Anderson, R. E., Tatham, R. L., \& Black, W. C. (1998). Multivariate data analysis (5 ${ }^{\text {th }}$ ed). Upper Saddle River, NJ: Prentice Hall.

Hong, W., Thong, J. Y. L., Wong, W. M., \& Tam, K. Y. (2002). Determinants of user acceptance of digital libraries: An empirical examination of individual characteristics and system characteristics. Journal of Management Information Systems, 18(3): 97-124.

Kaiser, H. F. (1974). An index of factorial simplicity. Psychometrika, 39:31-36.

Ministry of Education. (1998). Towards the Lifelong Learning Society --- White Paper. [Online] Available: http://study.ks.edu.tw/learn/low/low1.asp (October 2, 2009).

Nunnally, J. C., \& Bernstein, I. H. (1994). Psychometric theory (3rd ed.). New York: McGraw-Hill.

Wang, Xiaoxuan. (2004). Exploration into Information Technology and Instructional Design. Workshop Information, 21(3): 15-18.

Wu, Minglong \& Tu, Jintang. (2005). SPSS and Analysis of Statistical Application. Taipei: Wu-Nan.

Wu, Minglong. (2003). SPSS Statistical Application Practice. Taipei: Wenkui Information.

Wu, Minglong. (2007). Operation and Application of the Structural Equation Modeling AMOS. Taipei: Wu-Nan. 
Table 1. Code number of terms of pre-examined scale, content of the terms and their perspectives

\begin{tabular}{|c|c|c|}
\hline $\begin{array}{l}\text { Code } \\
\text { number } \\
\text { of terms }\end{array}$ & Content of terms & Perspectives \\
\hline $\mathrm{X} 1$ & $\begin{array}{l}\text { I may feel worried as a result of being unfamiliar with related products of information } \\
\text { technology. }\end{array}$ & \multirow{6}{*}{$\begin{array}{l}\text { Self-competence } \\
\text { difficulty }\end{array}$} \\
\hline $\mathrm{X} 2$ & $\begin{array}{l}\text { Information technology evolves at a tremendous pace, so I feel great pressure upon } \\
\text { learning of information technology. }\end{array}$ & \\
\hline $\mathrm{X} 3$ & $\begin{array}{l}\text { I am lacking in fundamental competence in application of information technology } \\
\text { tools (such as, communications, network and multi-media), so I feel confused about } \\
\text { information technology learning. }\end{array}$ & \\
\hline $\mathrm{X} 4$ & $\begin{array}{l}\text { I will feel ill at ease when I ask others about relevant questions on information } \\
\text { technology, so I feel confused about information technology learning. }\end{array}$ & \\
\hline X5 & $\begin{array}{l}\text { I may feel worried if information technology learning can not achieve its intended } \\
\text { target, so I feel confused about information technology learning. }\end{array}$ & \\
\hline X6 & $\begin{array}{l}\text { I may worry about wearing out new information technology products when I use } \\
\text { them, so I am not willing to learn information technology. }\end{array}$ & \\
\hline $\mathrm{X} 7$ & Learning new information technology may increase my burden on work. & \multirow{4}{*}{$\begin{array}{l}\text { Family } \\
\text { difficulty }\end{array}$} \\
\hline $\mathrm{X} 8$ & I have no extra time to learn new information technology knowledge. & \\
\hline X9 & $\begin{array}{l}\text { My family places too much hope upon me, which causes too much pressure upon my } \\
\text { learning of information technology. }\end{array}$ & \\
\hline $\mathrm{X} 10$ & $\begin{array}{l}\text { My family financial burden is too heavy, which affects my learning of information } \\
\text { technology. }\end{array}$ & \\
\hline $\mathrm{X} 11$ & $\begin{array}{l}\text { Information technology infrastructure is insufficient, which causes inconvenience in } \\
\text { my learning of information technology. }\end{array}$ & \multirow{5}{*}{$\begin{array}{l}\text { Information } \\
\text { support } \\
\text { difficulty }\end{array}$} \\
\hline $\mathrm{X} 12$ & $\begin{array}{l}\text { Instructions of operation are ambiguous, which affects my learning of information } \\
\text { technology. }\end{array}$ & \\
\hline $\mathrm{X} 13$ & $\begin{array}{l}\text { Deficiency in consultation and support of information professionals, which affects } \\
\text { my learning of information technology. }\end{array}$ & \\
\hline $\mathrm{X} 14$ & $\begin{array}{l}\text { I have difficulties in obtaining relevant information about information technology } \\
\text { learning. }\end{array}$ & \\
\hline $\mathrm{X} 15$ & $\begin{array}{l}\text { Relevant study courses about information technology have no means to satisfy my } \\
\text { personal demands. }\end{array}$ & \\
\hline
\end{tabular}


Table 2. Range of value and idea value of overall model fit index commonly used

\begin{tabular}{lll}
\hline Index & Scope of value & Ideal value \\
\hline $\begin{array}{l}1 . \chi^{2} \text { value } \\
\text { 2.GFI }\end{array}$ & Above 0 & Non-significant \\
3.PGFI & $0-1$ & At least above .9 \\
4.CFI & $0-1$ & Above .5 \\
5.AGFI & $0-1$ & Above $.9 ?$ \\
6. $\chi^{2} / d f$ & $0-1$, or negative value & At least above .9 \\
7. $\Delta_{1}(\mathrm{NFI})$ & Above 0 & Less than 3 \\
8. $\Delta_{2}(\mathrm{IFI})$ & $0-1$ & At least above .9 \\
9.TLI(NNFI) & Mostly $0-1$ & At least above .9 \\
$10 . \mathrm{SRMR}$ & $0-1$ & At least above .9 \\
$11 . \mathrm{RMSEA}$ & $0-1$ & Ought to below .05 \\
\hline
\end{tabular}

Table 3. Table of project analysis of the scale of information technology learning difficulties

\begin{tabular}{|c|c|c|c|c|c|c|c|}
\hline Number & $\begin{array}{c}\text { Project analysis } \\
\text { CR value (value } \\
\text { of } \mathrm{t} \text { ) }\end{array}$ & Significance & $\begin{array}{c}\text { Reserved } \\
\text { or not }\end{array}$ & Number & $\begin{array}{c}\text { Project analysis } \\
\text { CR value (value } \\
\text { of } \mathrm{t} \text { ) }\end{array}$ & Significance & $\begin{array}{c}\text { Reserved } \\
\text { or not }\end{array}$ \\
\hline $\mathrm{X} 1$ & 7.045 & .000 & Yes & X9 & 7.859 & .000 & Yes \\
\hline $\mathrm{X} 2$ & 10.210 & .000 & Yes & $\mathrm{X} 10$ & 7.008 & .000 & Yes \\
\hline $\mathrm{X} 3$ & 10.866 & .000 & Yes & $\mathrm{X} 11$ & 8.288 & .000 & Yes \\
\hline $\mathrm{X} 4$ & 9.927 & .000 & Yes & $\mathrm{X} 12$ & 9.142 & .000 & Yes \\
\hline $\mathrm{X} 5$ & 12.617 & .000 & Yes & $\mathrm{X} 13$ & 11.425 & .000 & Yes \\
\hline $\mathrm{X} 6$ & 9.419 & .000 & Yes & $\mathrm{X} 14$ & 11.861 & .000 & Yes \\
\hline $\mathrm{X7}$ & 10.817 & .000 & Yes & $\mathrm{X} 15$ & 6.253 & .000 & Yes \\
\hline $\mathrm{X} 8$ & 10.483 & .000 & Yes & & & & \\
\hline
\end{tabular}


Table 4. Abstract of analysis in factor structure and reliability of the scale of information technology learning difficulties

\begin{tabular}{ccccccc}
\hline $\begin{array}{c}\text { Names of } \\
\text { factors }\end{array}$ & $\begin{array}{c}\text { Number of } \\
\text { pre-examined } \\
\text { questionnaire questionnaire }\end{array}$ & $\begin{array}{c}\text { Number of } \\
\text { formal }\end{array}$ & $\begin{array}{c}\text { Factor } \\
\text { loadings }\end{array}$ & Eigenvalue & $\begin{array}{c}\text { Explained } \\
\text { variance }\end{array}$ & $\begin{array}{c}\text { Value of } \alpha \\
\text { in the } \\
\text { sub-scale }\end{array}$ \\
$\begin{array}{c}\text { Value of } \alpha \\
\text { in the scale }\end{array}$ \\
Self-competence \\
difficulty
\end{tabular}

Table 5. Results of analysis of overall model fit of the model after two confirmatory factor analyses

\begin{tabular}{|c|c|c|c|}
\hline \multicolumn{2}{|c|}{ Evaluation items } & \multirow{2}{*}{$\begin{array}{c}\begin{array}{c}\text { Before } \\
\text { correction }\end{array} \\
\text { No }\end{array}$} & \multirow{2}{*}{$\begin{array}{c}\begin{array}{c}\text { After } \\
\text { correction }\end{array} \\
\text { No }\end{array}$} \\
\hline \multirow{5}{*}{$\begin{array}{l}\text { Preliminary } \\
\text { fit criteria }\end{array}$} & Whether there is not any negative error variation? & & \\
\hline & Whether error variation is above the significance level? & Yes & Yes \\
\hline & Whether relevant absolute value of parameters is too close to $1 ?$ & Yes & Yes \\
\hline & Whether factor loadings are between .5 and $.95 ?$ & Yes & Yes \\
\hline & $\begin{array}{l}\text { There should not be any too high standard error of the parameter } \\
\text { estimated }\end{array}$ & Yes & Yes \\
\hline \multirow{11}{*}{$\begin{array}{l}\text { Overall } \\
\text { model fit } \\
\text { (external } \\
\text { quality) }\end{array}$} & Whether the GFI index is above $.9 ?$ & No & Yes \\
\hline & Whether the PGFI index is above $.5 ?$ & Yes & Yes \\
\hline & Whether GFI is above $9 ?$ & No & Yes \\
\hline & Whether AGFI index is above $9 ?$ & No & Yes \\
\hline & Whether the ratio of $\chi^{2} / d f$ value is below $3 ?$ & No & No \\
\hline & Whether $\Delta_{1}(\mathrm{NFI})$ index is above $.9 ?$ & No & Yes \\
\hline & Whether $\Delta_{2}$ (IFI) index is above $.9 ?$ & No & Yes \\
\hline & Whether TLI(NNFI) index is above $.9 ?$ & No & Yes \\
\hline & Whether SRMR index is below .05? & No & Yes \\
\hline & Whether RMSEA is below $.08 ?$ & No & Yes \\
\hline & Whether $\mathrm{CN}$ value is above $200 ?$ & No & Yes \\
\hline \multirow{3}{*}{\begin{tabular}{|l|} 
Internal \\
quality of \\
the model
\end{tabular}} & Whether constituent reliability of potential variables is above $.6 ?$ & No & Yes \\
\hline & Whether the estimated parameter is above the significance level? & Yes & Yes \\
\hline & Whether the absolute value of standardized residuals is below $2.58 ?$ & No & Yes \\
\hline
\end{tabular}


Table 6. Code number of terms of formal scale, content of the terms and their perspectives

\begin{tabular}{|c|c|c|}
\hline $\begin{array}{l}\text { Code } \\
\text { number } \\
\text { of terms }\end{array}$ & Content of terms & Perspectives \\
\hline $\mathrm{X} 1$ & $\begin{array}{l}\text { I may feel worried as a result of being unfamiliar with related products of information } \\
\text { technology. }\end{array}$ & \multirow{4}{*}{$\begin{array}{l}\text { Self-competence } \\
\text { difficulty }\end{array}$} \\
\hline $\mathrm{X} 2$ & $\begin{array}{l}\text { Information technology evolves at a tremendous pace, so I feel great pressure upon } \\
\text { learning of information technology. }\end{array}$ & \\
\hline $\mathrm{X} 3$ & $\begin{array}{l}\text { I am lacking in fundamental competence in application of information technology } \\
\text { tools (such as, communications, network and multi-media), so I feel confused about } \\
\text { information technology learning. }\end{array}$ & \\
\hline $\mathrm{X} 4$ & $\begin{array}{l}\text { I may feel worried if information technology learning can not achieve its intended } \\
\text { target, so I feel confused about information technology learning. }\end{array}$ & \\
\hline $\mathrm{X} 5$ & Learning new information technology may increase my burden on work. & \multirow{3}{*}{$\begin{array}{l}\text { Family } \\
\text { difficulty }\end{array}$} \\
\hline X6 & I have no extra time to learn new information technology knowledge. & \\
\hline $\mathrm{X} 7$ & $\begin{array}{l}\text { My family places too much hope upon me, which causes too much pressure upon my } \\
\text { learning of information technology. }\end{array}$ & \\
\hline $\mathrm{X} 9$ & $\begin{array}{l}\text { Information technology infrastructure is insufficient, which causes inconvenience in } \\
\text { my learning of information technology. }\end{array}$ & \multirow{4}{*}{$\begin{array}{l}\text { Information } \\
\text { support } \\
\text { difficulty }\end{array}$} \\
\hline $\mathrm{X} 10$ & $\begin{array}{l}\text { Instructions of operation are ambiguous, which affects my learning of information } \\
\text { technology. }\end{array}$ & \\
\hline $\mathrm{X} 11$ & $\begin{array}{l}\text { Deficiency in consultation and support of information professionals, which affects } \\
\text { my learning of information technology. }\end{array}$ & \\
\hline $\mathrm{X} 13$ & $\begin{array}{l}\text { Relevant study courses about information technology have no means to satisfy my } \\
\text { personal demands. }\end{array}$ & \\
\hline
\end{tabular}

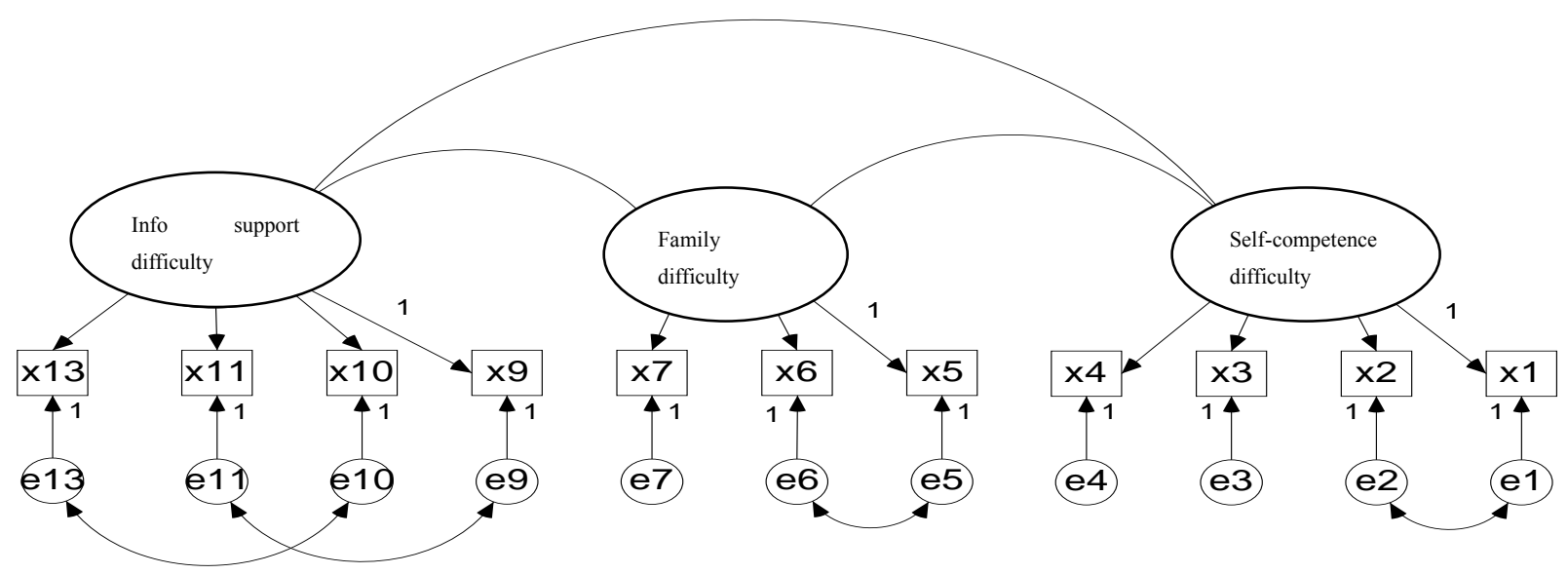

Figure 1. Diagram of the model corrected after confirmatory factor analysis 